\title{
Role of sensory nervous system vasoactive peptides in hypertension
}

\section{R.E. Watson, S.C. Supowit, \\ H. Zhao, K.A. Katki and D.J. DiPette}

\author{
Clinical Center, Michigan State University, East Lansing, MI, USA
}

\section{Correspondence \\ R.E. Watson \\ B 338 Clinical Center \\ Michigan State U niversity \\ East Lansing, MI 48824-1315 \\ USA \\ Fax: +1-517-432-1326 \\ E-mail: ralph.watson@ ht.msu.edu}

Presented at the IV International Symposium on Vasoactive Peptides, Belo Horizonte, MG, Brazil, October 19-21, 2001.

Research supported by the National Institutes of Health (NIH \# HL44277).

Received November 28, 2001 Accepted January 22, 2002

\section{Abstract}

The goal of the present research was to elucidate the roles and mechanisms by which the sensory nervous system, through the actions of potent vasodilator neuropeptides, regulates cardiovascular function in both the normal state and in the pathophysiology of hypertension. The animal models of acquired hypertension studied were deoxycorticosterone-salt (DOC-salt), subtotal nephrectomy-salt (SN-salt), and $\mathrm{N}^{\omega}$-nitro-L-arginine methyl ester (L-NAME)-induced hypertension during pregnancy in rats. The genetic model was the spontaneously hypertensive rat (SHR). Calcitonin gene-related peptide (CGRP) and substance P (SP) are potent vasodilating neuropeptides. In the acquired models of hypertension, CGRP and SP play compensatory roles to buffer the blood pressure (BP) increase. Their synthesis and release are increased in the DOC-salt model but not in the SN-salt model. This suggests that the mechanism by which both models lower $\mathrm{BP}$ in $\mathrm{SN}$-salt rats is by increased vascular sensitivity. CGRP functions in a similar manner in the L-NAME model. In the SHR, synthesis of CGRP and SP is decreased. This could contribute to the BP elevation in this model. The CGRP gene knockout mouse has increased baseline mean arterial pressure. The long-term synthesis and release of CGRP is increased by nerve growth factor, bradykinin, and prostaglandins and is decreased by $\alpha_{2}$-adrenoreceptor agonists and glucocorticoids. In several animal models, sensory nervous system vasoactive peptides play a role in chronic BP elevation. In the acquired models, they play a compensatory role. In the genetic model, their decreased levels may contribute to the elevated BP. The roles of CGRP and SP in human hypertension are yet to be clarified.

\section{Introduction}

Traditionally, the role of the sensory nervous system in blood pressure regulation has been through afferent baroreceptor-mediated mechanisms. There is now increasing evidence that, in addition to afferent mechanisms, the sensory nervous system plays a role in multiple areas (e.g., nociception and in-
Key words

- Hypertension

- Calcitonin gene-related peptide

- Substance P

- Neurons (afferent)

..................... flammation) through the efferent release of neuropeptides. Calcitonin gene-related peptide (CGRP) and substance P (SP) are neuropeptide mediators of sensory nervous system function. The present report will discuss the evidence for the role of the release of CGRP and SP by the sensory nervous system in the regulation of blood pressure and in experimental hypertension. 
CGRP is a 37-amino acid neuropeptide derived from the tissue-specific splicing of the primary RNA transcript of the calcitonin/CGRP gene $(1,2)$, which will be referred to as the $\alpha$-CGRP gene. Calcitonin is produced mainly in the parafollicular cells of the thyroid, but CGRP synthesis occurs almost exclusively in regions of the central and peripheral nervous systems (3). There is a second CGRP gene (B-CGRP) that does not produce calcitonin, and also produces CGRP primarily in central neuronal tissues $(3,4)$. The two CGRP genes, $\alpha$ - and $\beta$ - in the rat and I and II in humans, differ in their protein sequences by one and three amino acids, respectively, and the biological activities of the two peptides are quite similar in most vascular beds (5).

SP is an 11-amino acid peptide sensory neurotransmitter that mediates pain, touch, and temperature. Like CGRP, it is involved in many physiologic activities including smooth muscle contraction and vasodilation (5-8). SP is a member of the tachykinin family. The three major mammalian tachykinins are SP, neurokinin A (NKA), and neurokinin $\mathrm{B}$ (NKB) (9). SP and NKA are encoded by the preprotachykinin $\mathrm{A}$ gene, and NKB is encoded by the preprotachykinin B gene $(5,9,10)$. SP is often released from the same sensory nerve terminals as CGRP. SP has been shown to regulate blood flows of various organs.

\section{D istribution and localization of immunoreactive CGRP and substance $P$}

Immunoreactive (that which can react to the antibody in the assay) CGRP and SP and their receptors are widely distributed in the nervous and cardiovascular systems $(5,8,11)$. In the peripheral nervous system, prominent sites of CGRP and SP synthesis are in the spinal nerve dorsal root ganglia (DRG). These structures contain the cell bodies of sensory nerves that terminate centrally in laminae I/
II of the dorsal horn of the spinal cord and peripherally in blood vessels (11-13). Blood vessels in all vascular beds are surrounded by a dense perivascular CGRP and SP neural network. In these vessels CGRP- and SP-containing nerves are found at the junction of the adventitia and the media, passing into the muscle layer $(3,5)$. These peptides are often co-localized in the same peripheral nerve terminals. Circulating CGRP and SP are believed to be a spillover phenomenon from these perivascular nerve terminals caused by the release of these peptides to promote vasodilation or other functions (3). Receptors for CGRP have been identified both in the media and intima of resistance vessels. SP receptors and neurokinin-1 (NK-1) receptors, are found in endothelial cells (9).

\section{Cardiovascular actions of CGRP and substance $\mathbf{P}$}

CGRP is the most potent vasodilator discovered to date, and it has positive chronotropic and inotropic effects $(14,15)$. SP is also a potent vasodilator, but it has little effect on heart rate and contractility (9). CGRP selectively dilates many vascular beds, especially the coronary vasculature $(3,14$ 16). Systemic administration of CGRP decreases blood pressure in a dose-dependent manner in normotensive animals and humans $(3,11)$. The primary mechanism is peripheral arterial dilation $(3,11,15)$. The CGRP receptor(s) are coupled to $G$ proteins. $G$ proteins are located in the intracellular portion of the plasma membrane, and they bind activated receptor complexes. Through conformational changes and cyclic binding and hydrolysis of guanosine triphosphate, $\mathrm{G}$ proteins, directly or indirectly, effect alterations in channel gating, thus coupling cell surface receptors to intracellular responses. In a number of tissues, including vascular smooth muscle, CGRP increases intracellular cyclic adenosine monophosphate (cAMP). Other reports indicate that CGRP is capable 
of activating ATP-activated potassium channels of vascular smooth muscle (3). There is additional evidence that the vasodilator response evoked by CGRP is mediated, in part, by nitric oxide (NO) release and that various vascular beds differ in their dependence on the endothelium for the dilator response to CGRP (3). The vasodilator response mediated by NO is endothelium dependent, while the other mechanisms directly affect the vascular smooth muscle. Therefore, CGRP can dilate blood vessels through endotheliumdependent and -independent mechanisms.

The vasodilator action of SP is always endothelium dependent $(8,13)$ and is mediated by NK-1 receptors located in endothelial cells (9). There are three tachykinin receptor subtypes known as NK-1, NK-2, and NK3 . SP is the preferred ligand (binding molecule) for NK-1 receptors, NKA for NK-2, and NKB for NK-3, but all three tachykinins have some affinity for all three NK receptors if a high enough dose is given. The three receptors all belong to the superfamily of Gprotein-coupled receptors. Phosphoinositol is a cell membrane phospholipid. Each of these three receptors causes phosphoinositol breakdown, which initiates the vascular actions of the tachykinins. NK-1 receptors mediate tachykinin-induced vasodilation by an endothelium-dependent mechanism involving the release of both $\mathrm{NO}$ and a hyperpolarizing/vasodilator factor different from NO (9).

\section{Release of neuropeptides from sensory nerve terminals}

Sensory nerve fibers are classified as capsaicin (the active ingredient in pepper) sensitive and capsaicin insensitive. The capsaicin-sensitive nerves have the receptor for capsaicin. When capsaicin-sensitive sensory nerve fibers are exposed to capsaicin, they release CGRP and SP. CGRP- and SP-rich nerve fibers are components of the sensory nervous system, comprising principally cap- saicin-sensitive $\mathrm{C}$ - and $\mathrm{A} \delta$-fiber nerves that respond to chemical, thermal, and mechanical stimuli $(6,7,17,18)$. These stimuli cause release of CGRP and SP. If the stimulation is powerful enough, it also causes propagation of sensory information back to the central nervous system. Although these nerves have traditionally been thought to "sense" stimuli in the periphery and transmit the information centrally, there was early evidence that they also have an efferent function. It is clear that DRG neuron-derived peptides are released at peripheral sensory nerve terminals in the absence of afferent nerve stimulation (17). The continuous release of peptides from DRG neurons may reflect a paracrine function, with the released peptides binding to nearby receptors. This implies that these neurons participate in the continuous regulation of blood flow and other tissue activities. Indeed, it has been postulated that some DRG neurons are specialized in controlling peripheral effector mechanisms, but have no role in sensation (17). Sensory nerve terminals can release CGRP and SP in response to local factors including nerve growth factor (NGF) (19), vascular wall tension $(6,7)$, bradykinin/prostaglandins $(20,21)$, endothelin, and the sympathetic nervous system (21). We have demonstrated that these same factors which alter acute release of CGRP can also modulate the long-term production and release of this peptide. Using primary cultures of adult rat DRG neurons we have reported that NGF or bradykinin/prostaglandins $(20,22)$ can stimulate CGRP synthesis and release, whereas glucocorticoids (22) or $\alpha_{2}$-adrenoreceptor agonists (23) inhibit the stimulatory effects of NGF on CGRP. Thus, alterations in these factors, some of which are known to occur in hypertension, may mediate any changes seen in CGRP or SP synthesis and release.

\section{Role of CGRP in hypertension}

Although CGRP administration can sig- 
nificantly decrease high blood pressure in humans $(3,11)$, it is not clear what role CGRP plays in human hypertension. The reported levels of circulating immunoreactive CGRP in hypertensive humans have been conflicting $(3,11)$. This has been attributed to several factors including the assay itself, heterogeneity of the disease, severity and duration of the hypertension, the degree of end organ damage, and the variety of treatment regimens used in these patients (3). In contrast, a direct role for CGRP in experimental hypertension has now been established. Earlier reports demonstrated that CGRP can attenuate chronic hypoxic pulmonary hypertension (24). We studied CGRP in three animal models of hypertension: 1) deoxycorticosterone-salt (DOC-salt) model, a model in which the rat undergoes a uninephrectomy followed by excess mineralocorticoid and salt administration (25); 2) subtotal nephrectomy-salt (SN-salt) model, in which the rat undergoes a uninephrectomy plus surgical removal of $66 \%$ of the remaining kidney followed by excess salt administration (25), and 3) L-NAME-induced hypertension during pregnancy, in which the rat is given the NO inhibitor $\mathrm{N}^{\omega}$-nitro-L-arginine methyl ester (25). We have demonstrated for the first time that CGRP acts as a compensatory depressor mechanism to partially attenuate the blood pressure increase in these three models of experimental hypertension (26-30). Because these studies were done acutely, the important question regarding the long-term participation of CGRP in hypertension has not been answered.

\section{Role of substance $\mathbf{P}$ in hypertension}

SP is often co-localized and co-released with CGRP in sensory nerve terminals. The spontaneously hypertensive rat-stroke-prone strain (SHRSP) is a genetic model of experimental hypertension (25). Reduced levels of SP have been described in SHRSP and in human essential hypertension (31). There- fore, SP could contribute to the elevated blood pressure through the decreased activity of a counterregulatory mechanism. Kohlmann et al. (31) have employed a non-peptide SP receptor (NK-1) antagonist to assess the hemodynamic role of this peptide in five models of experimental hypertension. In addition to the DOC-salt and SN-salt models, they studied the SHR and two renovascular models, the "two-kidney, one-clip" and "onekidney, one-clip". In the first, both native kidneys are intact and a partially constricting clip is placed on one renal artery. In the second, the rat undergoes uninephrectomy, and a partially constricting clip is placed on the remaining renal artery (25). In conscious unrestrained rats the SP antagonist induced significant increases in mean arterial pressure (MAP) in three salt-dependent models, DOC-salt, SN-salt, and one-kidney, one-clip hypertensive rats. In contrast, the antagonist produced nonsignificant effects on the MAP in two-kidney, one-clip and SHR (salt-independent models). Therefore, SP may act as a partial compensatory mechanism to counteract the blood pressure increase in salt-dependent hypertension. The experiments described above were performed acutely, so the long-term participation of SP in hypertension is unknown.

\section{Hemodynamic effects of CGRP in experimental hypertension}

\section{Deoxycorticosterone-salt hypertension}

The first evidence that CGRP plays a role in hypertension was provided by studies using the DOC-salt rat. For these studies we used DOC-salt rats during the onset stage (three weeks after the initiation of the protocol) and four groups of normotensive rats to control for DOC-pellet implantation, uninephrectomy, and/or salt administration (Table 1). In our initial studies, we demonstrated that CGRP mRNA accumulation was significantly increased in DRG and correspond- 
ingly immunoreactive CGRP levels were elevated in laminae I/II of the spinal cord compared to the control groups (26). Furthermore, this increase in neuronal CGRP expression in the DOC-salt rats was specific for the DRG, since we did not observe any alterations in the brain or brain stem. In order to determine if these changes in CGRP were playing an important hemodynamic role, groups of rats had intravenous (for drug administration) and arterial (for continuous MAP monitoring) catheters surgically placed and were studied in the conscious, unrestrained state. Injection of saline did not alter MAP in any of the five groups and administration of the CGRP receptor antagonist $\mathrm{CGRP}_{8-37}$ did not significantly increase MAP in any of the four normotensive groups. However, administration of the antagonist to the DOC-salt rats rapidly induced, in a dosedependent manner, a further increase of the elevated MAP (Figure 1). In light of the rapid onset of the hypertensive effects of $\mathrm{CGRP}_{8-37}$ and because the antagonist probably does not penetrate the central nervous system, it is likely that the pressor activity of $\mathrm{CGRP}_{8-37}$ results from a direct interaction of the antagonist with vascular CGRP receptors (32-35). These data support the hypothesis that in DOC-salt hypertension CGRP is acting as a compensatory depressor to buffer the increased blood pressure (27).

\section{Subtotal nephrectomy-salt hypertension}

We examined the effect of endogenous CGRP on blood pressure in SN-salt-induced hypertension, another model of low-renin, salt-dependent hypertension (28). SN-salt and normotensive controls were instrumented and given saline or $\mathrm{CGRP}_{8-37}$ as described above (Figure 2). The effects of two different doses of $\mathrm{CGRP}_{8-37}$ in the control group were similar to those observed with saline, which did not significantly alter the MAP. In contrast, administration of antagonist to the SN-salt rats produced a dose-dependent increase of the elevated MAP, similar to what was observed in the DOC-salt rats. These results suggest that, in this setting, CGRP is also playing a compensatory depressor role. Surprisingly, when the CGRP mRNA and peptide levels were quantified in the DRG from hypertensive and control rats there were no detectable changes. These results suggested a second mechanism by which CGRP exerts its counterregulatory action. As opposed to increased CGRP synthesis and release, this effect may be mediated through an increase in the vascular responsiveness to CGRP. Indeed, additional experiments indicate that vascular reactivity to CGRP is enhanced in $\mathrm{SN}$-salt rats (36).

\section{L-NAM E-induced hypertension}

The purpose of the following experiments was to determine whether CGRP is involved in the vascular adaptations that occur in normal pregnancy and its role in the hypertension of L-NAME-treated female rats. Inhibition of NO synthesis with L-NAME in pregnant rats has been shown to cause hypertension, proteinuria, fetal growth retardation, and increased fetal mortality (37). The co-administration of CGRP with L-NAME prevented the gestational, but not the postpartum hypertension (37). It also prevented the proteinuria and significantly decreased pup mortality (37). Further studies revealed that this differential effect of CGRP on blood

Table 1. Summary of the DOC-salt (group A) and normotensive control groups (B-E) studied.

\begin{tabular}{|c|c|c|c|c|c|}
\hline Group (N) & $A(7)$ & $B(7)$ & $C(5)$ & $\mathrm{D}(6)$ & $E(6)$ \\
\hline Surgery & NX & Sham & $N X$ & Sham & $\mathrm{NX}$ \\
\hline Diet & Salt & Water & Water & Salt & Salt \\
\hline Implant & DOC & Placebo & Placebo & Placebo & Placebo \\
\hline Final MAP & $174.7 \pm 5.4^{*}$ & $109.4 \pm 4.1$ & $125.1 \pm 4.6$ & $114.2 \pm 2.7$ & $125.4 \pm 4.8$ \\
\hline
\end{tabular}

$\mathrm{NX}=$ left nephrectomy; DOC $=$ deoxycorticosterone-acetate pellet; salt $=0.9 \% \mathrm{NaCl} /$ $0.2 \% \mathrm{KCl}$ drinking water; MAP $=$ mean arterial pressure $(\mathrm{mmHg})$. Values for MAP are reported as mean $\pm \mathrm{SEM}$. $* \mathrm{P}<0.001$ compared to each of the four control groups (ANOVA followed by the Tukey-Kramer multiple comparisons test). 
Figure 1. The calcitonin gene-related peptide receptor antagonist $\mathrm{CGRP}_{8-37}$ increases mean arterial pressure (MAP) in deoxycorticosterone (DOC)-salt hypertensive rats but not normotensive controls. Rats were instrumented for continuous MAP recording and antagonist administration as described in the text. With the rats fully awake and unrestrained, bolus doses of the indicated amounts of $\mathrm{CGRP}_{8-37}$ were given. ${ }^{*} \mathrm{P}>0.01$, higher vs lower dose of CGRP 8-37. $* * P<0.001$, DOC-salt (group A) vs each of the four controls at both CGRP $_{8-37}$ doses (ANOVA followed by the Tukey-Kramer multiple comparisons test).

Figure 2. The calcitonin generelated peptide receptor antagonist $\mathrm{CGRP}_{8-37}$ increases mean arterial pressure (MAP) in the subtotal nephrectomy (SN)-salt hypertensive rats but not normotensive controls. Rats were instrumented for continuous MAP recording and antagonist administration. With the rats fully awake and unrestrained, bolus doses of the indicated amounts of CGRP 8 -37 were given intravenously. $* \mathrm{P}<0.05$, $\mathrm{SN}$-salt hypertensive vs control rats at the lower $\mathrm{CGRP}_{8-37}$ dose. $* * \mathrm{P}<0.01$, SN-hypertensive vs control rats at the higher CGRP 8-37 dose (ANOVA followed by the Tukey-Kramer multiple comparisons test).

Figure 3. The calcitonin generelated peptide receptor antagonist CGRP8-37 increases mean arterial pressure (MAP) in the $\mathrm{N}^{\omega}$-nitro-L-arginine methyl ester (L-NAME)-treated pregnant rats. Animals were instrumented for continuous MAP recording and $\mathrm{CGRP}_{8-37}$ administration on days 19, 20, and 21 (D19-21) of pregnancy and postpartum day 1 (P1). With the animals in a fully awake and unrestrained state, bolus doses of $100 \mu \mathrm{g}$ $\mathrm{CGRP}_{8-37}$ were given. $* \mathrm{P}<0.05$ compared to control animals (ANOVA followed by the TukeyKramer multiple comparisons test).
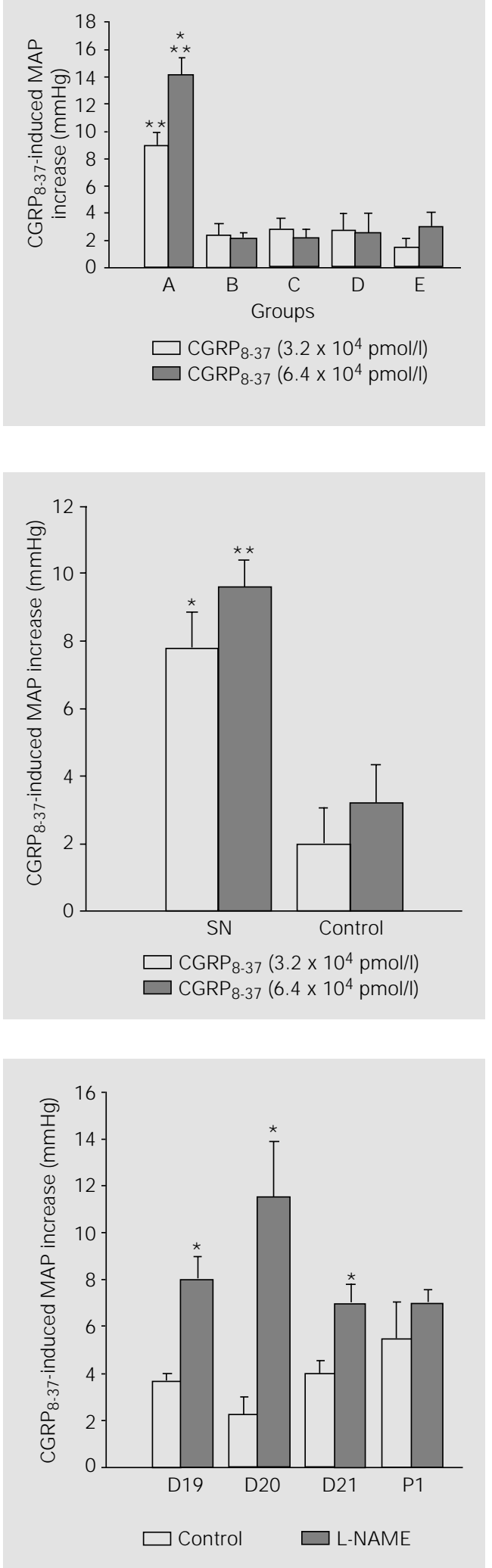

pressure during gestation and postpartum is mediated by progesterone (38). Gestational progesterone is high, while postpartum progesterone is low. Similar to the findings in gestational rats, CGRP reversed the hypertension in L-NAME-treated oophorectomized rats receiving progesterone injections. Therefore, these studies suggest that CGRP is anti-hypertensive in L-NAME-treated pregnant and non-pregnant rats and that the vasodilator effects of CGRP are modulated by progesterone. To determine whether endogenous CGRP participates in blood pressure regulation in the L-NAME-treated pregnant rats, the CGRP antagonist $\left(\mathrm{CGRP}_{8-37}\right)$ was given to L-NAME-treated control pregnant rats, starting on day 17 of gestation (Figure 3) (37). The effect of CGRP ${ }_{8-37}$ is brief (a few minutes), so each day has its own baseline blood pressure. The baseline blood pressure was higher in the L-NAME than in the control rats on days 19, 20, and 21 of pregnancy and on postpartum day $1 . \mathrm{CGRP}_{8-37}$ did not change blood pressure in the control groups. However, antagonist administration to the L-NAME rats further increased blood pressure on days 19,20, and 21 of pregnancy but had no effect on postpartum day 1 . Furthermore, CGRP mRNA and peptide levels in DRG were not different between the LNAME and control rats at any of the time points studied. These data indicate that CGRP also plays a counterregulatory role in a saltindependent model. Although the mechanism by which this occurs has not been elucidated, it appears that the sensitivity of the vasculature to CGRP is enhanced in this model, with no increase in CGRP synthesis. This is mediated, at least in part, by progesterone.

\section{Spontaneously hypertensive rats}

We previously demonstrated that the agerelated decrease in neuronal CGRP expression in the SHR could contribute to the elevated blood pressure. NGF has been shown 
to be a stimulant of CGRP synthesis in DRG. We therefore proposed that NGF administration to SHR would decrease blood pressure through the stimulation of CGRP synthesis in DRG. NGF (10 $\mathrm{ng} \mathrm{kg}^{-1}$ day $\left.^{-1}\right)$ was administered by intraperitoneal injection to 12-week-old SHR (39). NGF was given once a day for 1, 3, and 7 days. A separate group of control SHR received vehicle only. At the end of each treatment period the animals were instrumented for continuous MAP recording and infusion of saline or $\mathrm{CGRP}_{8-37}$. After a single NGF treatment (day $1, \mathrm{~N}=8$ ), the MAP was reduced by $21 \pm 2 \mathrm{mmHg}$ compared to the control SHR. The MAP was still reduced by $22 \pm 3 \mathrm{mmHg}$ on day $3(\mathrm{~N}=$ $9)$; however, by day $7(\mathrm{~N}=11)$ the MAP was back up to control levels $(169 \pm 5 \mathrm{mmHg}$ ). To determine whether any of the MAP reduction observed on days 1 and 3 was due to CGRP, during the course of the MAP determinations each animal was treated intravenously (iv) with either saline or the CGRP receptor antagonist $(200 \mu \mathrm{g})$. Saline treatment produced a negligible increase in MAP at all the time points studied (Figure 4). In the control SHR, $\mathrm{CGRP}_{8-37}$ treatment resulted in a $3.4 \pm 1.2 \mathrm{mmHg}$ increase in MAP which was similar to what was seen with saline. However, on days 1 and 3 of NGF treatment $\mathrm{CGRP}_{8-37}$ produced a $12.7 \pm 2.2$ and $11.6 \pm$ $2.1 \mathrm{mmHg}$ increase in MAP, respectively. Unexpectedly, on day 7 when the MAP was back up to control levels, antagonist treatment still resulted in an $11.7 \pm 2.4 \mathrm{mmHg}$ increase in MAP. When we examined CGRP mRNA levels in DRG from the control and NGF-treated rats, there was a significant two-fold increase on days 1, 3, and 7 in the NGF-treated group only (Figure 5). CGRP peptide levels in DRG displayed a similar increase (39). Therefore, NGF treatment on days 1 and 3 produces a significant $21 \mathrm{mmHg}$ decrease in MAP. About half of this MAP reduction is due to CGRP as determined by blockade of the CGRP receptor. This action of CGRP most likely results from the en- hanced release and production of this peptide. These results (days 1 and 3) strongly suggest that the decreased production of CGRP that is observed in SHR could contribute to the elevated blood pressure. After a week of NGF treatment CGRP synthesis is elevated. Antagonist administration indicates that CGRP is continuing to play a compensatory role, but the MAP has returned to control levels. The continued activity of $\mathrm{CGRP}_{8-37}$ argues against down-regu-
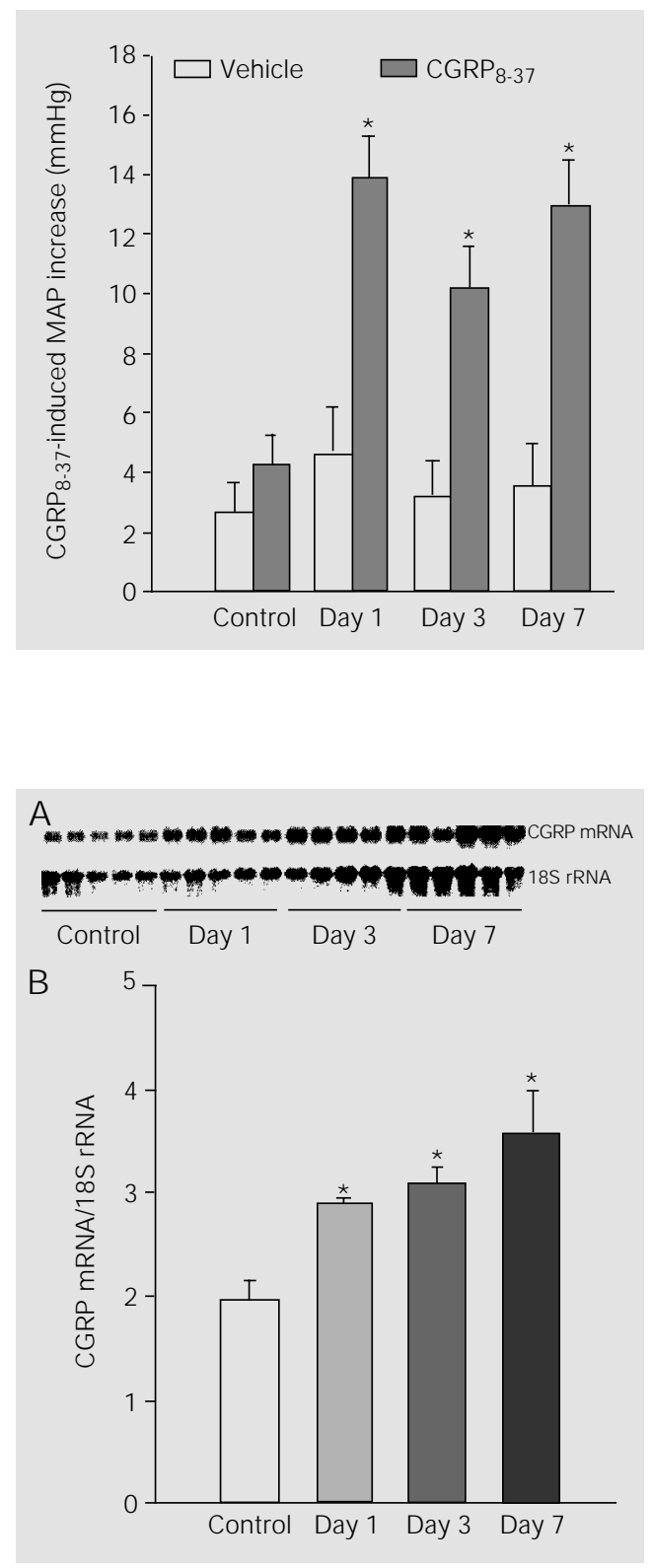

Figure 4. Calcitonin gene-related peptide (CGRP) receptor antagonist administration increases mean arterial pressure (MAP) in the nerve growth factor (NGF)treated but not the control spontaneously hypertensive rats (SHR). Control $(\mathrm{N}=8)$ and NGFtreated (days $1, \mathrm{~N}=9 ; 3, \mathrm{~N}=10$, and $7, \mathrm{~N}=11$ ) SHR were instrumented for continuous MAP recording and intravenous drug administration. With the rats fully awake and unrestrained, bolus doses of saline $(200 \mu \mathrm{l})$ or CGRP $_{8-37}(800 \mu \mathrm{g} / \mathrm{kg}$ in $200 \mu \mathrm{l}$ saline) were given intravenously. $* \mathrm{P}<0.05$ compared to control SHR (ANOVA followed by the Tukey-Kramer multiple comparisons test).

Figure 5. Northem blot analysis of RNA samples from the control and nerve growth factor-treated spontaneously hypertensive rats. A, Total cellular RNA samples were fractionated on denaturing formaldehyde-agarose gel and transferred to a nylon membrane. The membrane was hybridized with the ${ }^{32} \mathrm{P}$-labeled calcitonin gene-related peptide (CGRP) genomic DNA insert. The CGRP probe was removed from the membrane, which was subsequently hybridized with the ${ }^{32} \mathrm{P}$ labeled 18S rRNA probe. After hybridization with each probe, the membrane was washed and placed in a phosphor screen cassette. The exposed phosphor screen was then placed in a phosphor imager to quantify the hybridization signals as shown in panel B. $* P<0.05$ compared to control animals (ANOVA followed by the Tukey-Kramer multiple comparisons test). 
lation of the CGRP receptor as the cause for the increase in MAP on day 7. One possibility is that the enhanced production of CGRP is acting to decrease the MAP on days 1, 3, and 7 . However, by day 7, NGF may have stimulated a pressor system to counteract the depressor effects of CGRP and bring the MAP back up to control levels. Two candidates are the sympathetic nervous system and neuropeptide $\mathrm{Y}$, both of which are upregulated by NGF (39).

\section{Characterization of the $\alpha$-CGRP knockout mouse}

Dr. Robert Gagel (Baylor College of Medicine) provided us with homozygous $\alpha$ CGRP knockout (KO) mice from breeding pairs generated by gene targeting of the calcitonin/ $\alpha$-CGRP gene (40). The $\beta$-CGRP gene is intact in $\mathrm{KO}$ mice; however, $\alpha$-CGRP is by far the predominant CGRP form produced in DRG neurons (3). For our initial studies, systolic blood pressures were determined using a mouse tail-cuff blood pressure apparatus. Using this protocol it was determined that the systolic blood pressure was significantly $(\mathrm{P}<0.01)$ higher in $\mathrm{KO}$ mice $(\mathrm{N}=9 ; 160 \pm 6.1 \mathrm{mmHg})$ compared to controls $(\mathrm{N}=10 ; 125 \pm 4.8 \mathrm{mmHg})(41)$. Having observed that the systolic blood pres-

Figure 6. Mean arterial pressure (MAP) determinations made with an indwelling carotid arterial catheter in calcitonin gene-related peptide knockout (CGRP$\mathrm{KO})$ ( $\mathrm{N}=7 / \mathrm{group}$ ) and wild-type ( $N=7 /$ group) mice of either sex, in a fully awake and unrestrained state. ${ }^{*} \mathrm{P}<0.05$ compared to wild-type animals (ANOVA followed by the Tukey-Kramer multiple comparisons test).

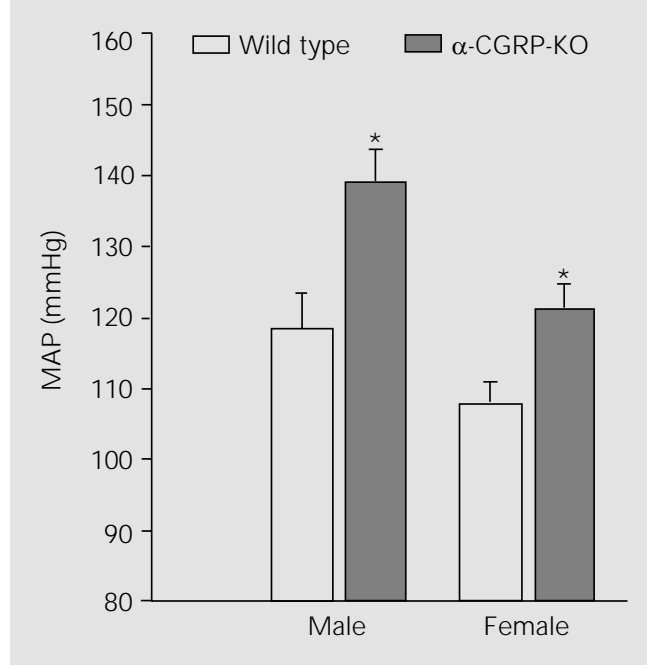

sure was elevated in $\mathrm{KO}$ mice, it was necessary to then determine whether this was reflected in the MAP. KO $(\mathrm{N}=9)$ and wildtype control $(\mathrm{N}=9)$ mice $(25-30$ g males $)$ were anesthestized with ketamine/xylazine and the right carotid artery was cannulated with P-10 tubing that was connected to a Gould pressure transducer and recorder. Continuous MAP measurements were made with the mice fully awake and unrestrained. As shown in Figure 6, the MAP was significantly elevated in $\mathrm{KO}$ mice $(139 \pm 4.9 \mathrm{mmHg})$ compared to controls $(118 \pm 4.9 \mathrm{mmHg})$ (41). After the MAP determinations the mice were sacrificed and the DRG were removed and frozen for later quantification of $\alpha$ CGRP, B-CGRP, and SP mRNA and peptide levels.

To address the question of whether the KO mice would have an enhanced sensitivity to CGRP, pilot studies were performed in which the mice were instrumented as described above, except that the jugular vein was also cannulated for administration of saline or CGRP. Administration of saline $(0.1 \mathrm{ml})$ produced a negligible increase in MAP in both the $\mathrm{KO}(\mathrm{N}=4)$ and wild-type $(\mathrm{N}=4)$ mice. Administration of an $i v$ bolus dose of rat $\alpha$-CGRP (1.5 ng/g body weight) resulted in a rapid $16.3 \pm 4.3 \mathrm{mmHg}$ decrease in MAP in the wild-type mice and a $29.5 \pm 4.4 \mathrm{mmHg}$ reduction in the $\mathrm{KO}$ mice. These results indicate that the $\mathrm{KO}$ mice have an increased sensitivity to CGRP. DRG tissue from the two groups of mice was then processed to evaluate $\alpha$-CGRP, $\beta$-CGRP, and SP mRNA levels. There was no $\alpha$-CGRP mRNA in the KO mice following Northern blot analysis, whereas the 18S rRNA can be seen in the DRG RNA samples from both groups of mice. This demonstrates that the Northern blot analysis was performed correctly. Experiments were also performed to determine if B-CGRP and SP mRNA levels were altered between the $\mathrm{KO}$ and wild-type mice in the absence of a challenge to blood pressure homeostasis. As expected, the 
mRNA species for B-CGRP and SP were present in both groups and normalization of the hybridization signals (ß-CGRP and SP) to $18 \mathrm{~S}$ rRNA levels indicated that there was no significant change in the synthesis of these mRNAs. This indicates that only the $\alpha$ CGRP gene is missing in these $\mathrm{KO}$ mice. Immunostaining for immunoreactive CGRP was performed in the spinal cords of both $\mathrm{KO}$ and control mice. There was intense staining of CGRP in laminae I/II of the dorsal horn of the spinal cord in the wild-type mice. Even though the antibody used in these studies recognizes both $\alpha$ - and $\beta$-CGRP, no staining is observed in the cords of the $\mathrm{KO}$ mice, because of the lack of $\alpha$-CGRP expression and the very low levels of $\beta$-CGRP that are produced in DRG (41).

\section{Role of substance $P$ in subtotal nephrectomy-salt and deoxycorticos- terone-salt induced hypertension in the rat}

As described previously, Kohlmann et al. (31) reported that SP plays a compensatory role to buffer the blood pressure increase in SN-salt, DOC-salt, and one-kidney, one-clip rats. They did not determine whether SP expression in DRG was significantly increased in any of these models. We have since confirmed an antihypertensive role for SP in the SN- and DOC-salt rats (42). We utilized the SP receptor antagonist Spantide-II (Span-II). In DOC-salt rats $i v$ Span-II caused a rapid increase in MAP compared to controls $(9.3 \pm 1.5$ vs $0.9 \pm 2.2$ mmHg) (42). In SN-salt rats, iv Span-II also significantly elevated MAP $(13.9 \pm 0.8 v s$ $1.7 \pm 1.7 \mathrm{mmHg}$ ) (43). Our studies also suggested that the depressor effect of SP is mediated, at least in part, through the interaction of SP with vascular NK-1 receptors. Quantification of DRG SP mRNA and peptide levels revealed no significant increase in $\mathrm{SP}$ mRNA or protein in the $\mathrm{SN}$-salt rats $(\mathrm{N}=$ 8) compared to two groups ( $\mathrm{N}=8$ /group) of controls (sham operated with either tap water or saline drinking water) (43). This is similar to what was found for CGRP expression in this setting. In contrast, SP mRNA in DRG was significantly increased in the DOCsalt rats $(\mathrm{N}=9)$ compared with the control group (sham operated with tap water to drink, $\mathrm{N}=7)(6.5 \pm 0.4 v s 4.4 \pm 0.7$ arbitrary units $)$ (42). SP peptide content in DRG was also significantly increased in DOC-salt rats compared to controls $(0.26 \pm 0.03$ vs $0.18 \pm 0.01$ $\mathrm{pg} \mathrm{SP} / \mu g$ protein) (42). Again, this is similar to what was found for CGRP, although the increase in SP expression was not nearly as robust as that for CGRP (4.5-fold). These results suggested that an increase in vascular reactivity to SP was responsible, at least in part, for the antihypertensive activity of this peptide in both models. To evaluate this possibility, additional groups of SN-salt (N $=6)$ and control $(\mathrm{N}=6)$ rats were instrumented for MAP recording and drug administration. With the animals fully awake and unrestrained, $\mathrm{SP}(12 \mathrm{nM} / \mathrm{kg})$ administration produced a $17 \pm 3 \%$ fall in baseline MAP in the control group and a significant $26 \pm 4 \%$ decrease in the $\mathrm{SN}$-salt rats. Also, administration of the same dose of SP to DOC-salt $(\mathrm{N}=7)$ and control $(\mathrm{N}=7)$ rats caused a decrease in MAP of $14 \pm 4$ and $29 \pm 5 \%$, respectively. This indicates that an increase in vascular responsiveness to SP is one mechanism by which SP exerts its depressor effects in both SN- and DOC-salt hypertension. These results also provide additional evidence for a counterregulatory role for SP.

\section{Development of the adult rat dorsal root ganglion neuron primary culture model system}

As described previously, we have demonstrated that sensory neuropeptide expression (production and release) can be significantly altered in several models of experimental hypertension $(26,28,31,39,42)$. In order to identify the regulatory factors and 
mechanisms that modulate long-term expression of CGRP and SP in vivo, it was necessary to develop an in vitro model system using primary cultures of DRG neurons. Lindsay (44) previously reported that in cultured adult DRG neurons, NGF stimulates the expression of CGRP and SP. Importantly, the induction of these peptides was not mediated indirectly through the non-neuronal cells nor was it the result of a survival-promoting effect of NGF. We have also established the conditions for the dissociation and maintenance of adult DRG neurons in both serum and serum-free conditions. All of the in vitro studies described herein were performed under serum-free conditions. Using immunocytochemical staining we initially showed that CGRP synthesis is restricted to approximately $40 \%$ of the neuronal cell population in the DRG (22). This is comparable to the values reported by other investigators. To determine if our preparations of neurons were also responsive to NGF, we treated the cultures with NGF $(50 \mathrm{ng} / \mathrm{ml}$ ) (Supowit SC and $\mathrm{Zhao} \mathrm{H}$, unpublished results). We found that CGRP mRNA content was increased 3.4-fold at $24 \mathrm{~h}$ and 5.7-fold after $48 \mathrm{~h}$. NGF treatment also increased immunoreactive CGRP release 3.1- and 4.6-fold at these same time points. Further, in vitro characterization of the actions of NGF revealed a strict dose-dependent $(5-200 \mathrm{ng} / \mathrm{ml})$ increase in CGRP mRNA and peptide release.

To determine the effect of activation of two primary intracellular signal transduction pathways on CGRP production and release, neuronal cultures were treated with dibutyryl cAMP or phorbol 12-myristate 13-acetate (PMA), a protein kinase A activator and protein kinase $\mathrm{C}$ activator, respectively (22). Exposure of the cultures to either dibutyryl cAMP or PMA for $24 \mathrm{~h}$ increased CGRP mRNA accumulation 2.2- and 3.0-fold while immunoreactive CGRP release was stimulated 2.0and 4.8-fold. This was the first demonstration that these agents could directly regulate CGRP mRNA production and immunoreactive CGRP release in DRG neurons. These data indicate that local or circulating factors that act to regulate neuronal cell function through protein kinase $\mathrm{A}$ and $\mathrm{C}$ signal transduction pathways also modulate CGRP expression. These second messenger pathways have been implicated in NGF, bradykinin/prostaglandin, and $\alpha_{2}$-adrenoreceptor agonist actions (45). Since all of these factors have been shown to be altered in either SHR and/or DOC-salt hypertension, and have also been implicated in the regulation of CGRP expression, it was possible to determine in vitro if these agents could directly modulate CGRP synthesis and/or release.

\section{Mechanisms by which nerve growth factor, the sympathetic nervous system, and glucocorticoids interact to regulate neuronal CGRP expression}

Several lines of evidence indicate that $\alpha_{2}$ adrenoreceptor agonists and glucocorticoids inhibit the acute release of CGRP from sensory nerve terminals (23). To test this possibility in vitro, we employed primary cultures of adult rat DRG neurons. Neuronal cultures were initially exposed (24 h) to either the $\alpha_{2}$ adrenoceptor agonist UK 14,304 $(1 \mu \mathrm{M})$ or vehicle; however, no changes in CGRP mRNA content or immunoreactive CGRP release were observed (23). Using the rationale that in vivo DRG neurons receive a continuous supply of target tissue-derived NGF, which stimulates CGRP synthesis, the neurons were treated (24 h) with vehicle, NGF $(25 \mathrm{ng} / \mathrm{ml})$ alone, or NGF plus UK. NGF treatment increased CGRP mRNA accumulation 5.5-fold and immunoreactive CGRP release 3.0-fold over control levels. The stimulatory effects of NGF were markedly inhibited but not abolished by UK (NGF + UK vs control, CGRP mRNA 2.9fold; immunoreactive CGRP, 1.7-fold). These values were also significant when compared to NGF treatment alone. Experiments using the $\alpha_{2}$-antagonist yohimbine confirmed that the effects of UK were mediated by the $\alpha_{2}$ - 


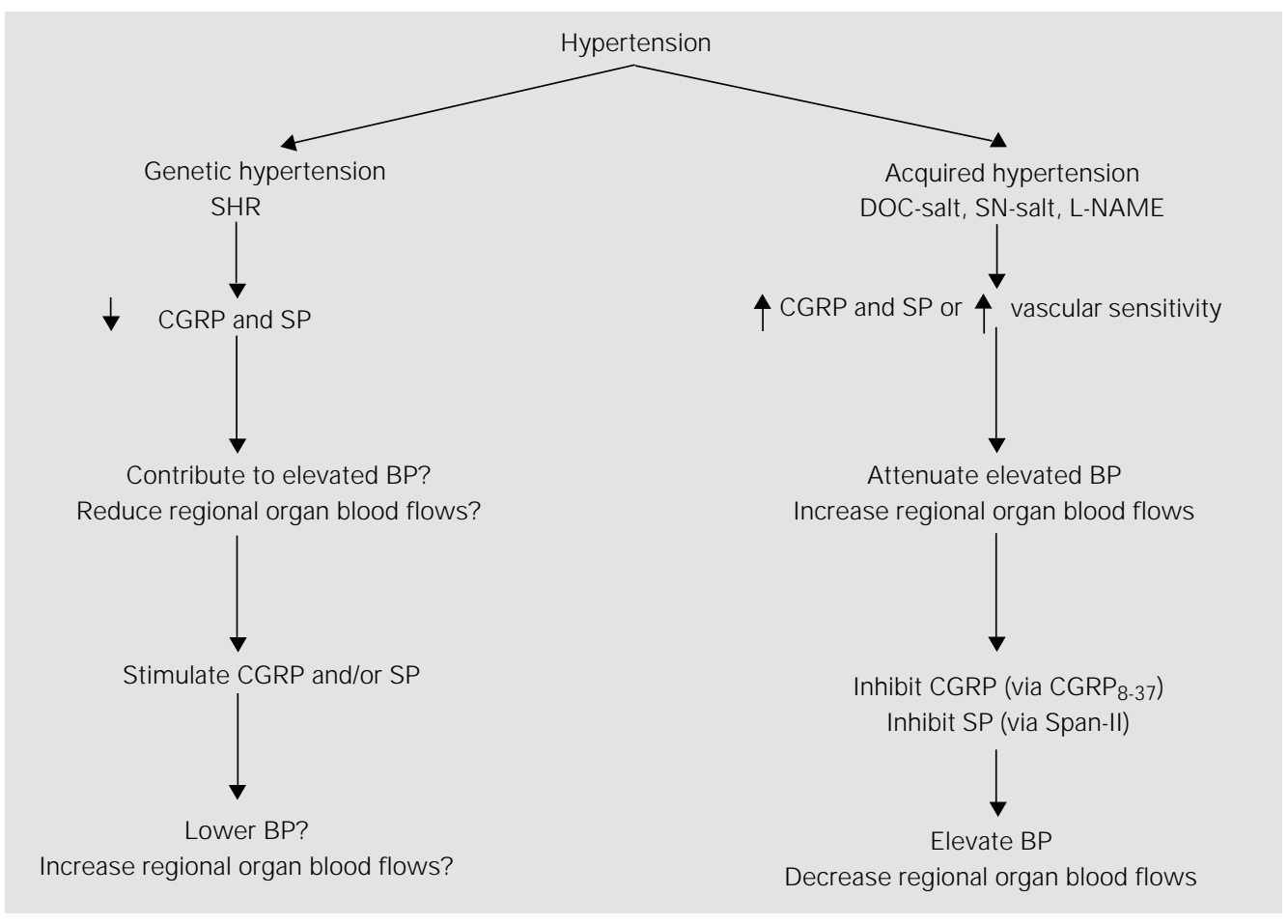

Figure 7. Proposed role(s) of calcitonin gene-related peptide (CGRP) and substance $P$ (SP) in experimental hypertension. SHR: spontaneously hypertensive rats; BP: blood pressure; DOC-salt, SN-salt and L-NAME-induced hypertension: deoxycorticosterone, subtotal nephrectomy and $\mathrm{N}^{\omega}$-nitro-L-arginine methyl ester, respectively; Span-II: SP receptor antagonist Spantide-II.

adrenoceptor. Likewise, the inhibitory effects of dexamethasone on CGRP expression were mediated by the attenuation of the stimulatory effects of NGF. Although the mechanism that mediates this phenomenon is not known, these data suggest that inhibition of stimulated rather than basal expression of CGRP (and possibly $\mathrm{SP}$ ) is a common theme underlying the negative regulation of neuropeptide synthesis and release in sensory neurons. In addition, the results of the $\alpha_{2}$-adrenoceptor agonist studies support the argument that in the SHR the hyperinnervation of the vasculature by the sympathetic nervous system is responsible, at least in part, for the reduction of CGRP production that is observed in this setting.

\section{Regulation of neuronal CGRP expres- sion by the bradykinin/prostaglandin system}

Several lines of evidence suggest that the enhanced activity of the kallikrein/kinin system observed during the onset phase of DOCsalt hypertension is partly responsible for the up-regulation of CGRP expression that is observed in this model. In vitro testing of this hypothesis using the DRG primary culture system showed for the first time that bradykinin and selective prostanoids were potent stimulators of long-term CGRP synthesis and release. Moreover, these studies demonstrated that the effects of bradykinin were mediated entirely through the cyclooxygenase-mediated increase in prostaglandin production. These data have been published in abstract form (20).

\section{Conclusion}

In several animal models, sensory nervous system vasoactive peptides seem to play a role in chronic blood pressure elevation. In the acquired models, they play a 
compensatory role. In the genetic model, their decreased levels may contribute to the elevated blood pressure, as illustrated in Figure 7. The roles of CGRP and SP in human hypertension are yet to be clarified.

\section{Acknowledgments}

We would like to thank Ms. Rebecca McMahon for clerical assistance with this paper.

\section{References}

1. Amara SG, J onas V, Rosenfeld MG \& Evans RM (1982). Alternative RNA processing in calcitonin gene expression generates mRNA encoding different polypeptide products. Nature, 298: 240-244.

2. Rosenfeld MG, Mermod J J Amara SG, Swanson LW, Rivier PE, Vale WW \& Evans RM (1983). Production of a novel neuropeptide encoded by the calcitonin gene via tissue-specific RNA processing. Nature, 304: 129-133.

3. Wimalawansa SJ (1996). Calcitonin generelated peptide and its receptors: molecular genetics, physiology, pathophysiology, and therapeutic potentials. Endocrine Reviews, 17: 533-585.

4. Breimer LH, Maclntyre I \& Zaidi M (1988). Peptides from the calcitonin genes: molecular genetics, structure, and function. Biochemical J ournal, 255: 377-390.

5. Dockray GJ (1994). Physiology of enteric neuropeptides. In: J ohnson LR (Editor), Physiology of the Gastrointestinal Tract. Raven Press, New York, NY, USA.

6. Lembeck F \& Holzer P (1979). Substance $P$ as a neurogenic mediator of antidromic vasodilation and neurogenic plasma extravasation. Naunyn-Schmiedeberg's Archives of Pharmacology, 310: 175-183.

7. Holzer P (1988). Local effector functions of capsaicin-sensitive sensory nerve endings: involvement of tachykinins, calcitonin gene-related peptide, and other neuropeptides. Neuroscience, 24: 739-768.

8. Yaksh TL, Bailey J E \& Roddy DR (1988). Peripheral release of substance $P$ from primary afferents. In: Dubner R, Gebhart GF \& Bond MR (Editors), Proceedings from the Vth World Congress on Pain. Elsevier, Amsterdam, Netherlands.

9. Maggi CA (1995). The mammalian tachykinin receptors. General Pharmacology, 26: 911-944.

10. Brown MJ \& Morice AH (1987). Clinical pharmacology of vasodilator peptides. J ournal of Cardiovascular Pharmacology, 10: $582-590$

11. DiPette DJ \& Wimalawansa SJ (1994). Cardiovascular actions of calcitonin generelated peptide. In: Crass J \& Avioli LV
(Editors), Calcium Regulating Hormones and Cardiovascular Function. CRC Press, Ann Arbor, MI, USA.

12. Gibson SJ, Polak J M, Bloom SR, Sabate IM, Mulderry PM, Ghatei MA, McGregor GP, Morrison J F, Kelly J S \& Evans RM (1984). Calcitonin gene-related peptide immunoreactivity in the spinal cord of man and of eight other species. J oumal of Neuroscience, 4: 3101-3111.

13. Marti E, Gibson SJ, Polak J M, Facer $P$, Springall DP, Aitchison M \& Koltzenburg M (1987). Ontogeny of peptide- and amine-containing neurones in motor, sensory and autonomic regions of rat and human spinal cord, dorsal root ganglia and rat skin. J ournal of Comparative Neurology, 226: 332-359.

14. Asimakis GK, DiPette DJ, Conti VR, Holland OB \& Zwishenberger J B (1987). Hemodynamic action of calcitonin gene-related peptide in the isolated rat heart. Life Sciences, 41: 597-603.

15. DiPette DJ , Schwarzenberger K, Kerr N \& Holland OB (1989). Dose dependent systemic and regional hemodynamic effects of calcitonin gene-related peptide. American J ournal of the Medical Sciences, 297: 65-70.

16. Brain SD, Williams TJ , Tippins J R, Morris HR \& MacIntyre I (1985). Calcitonin generelated peptide is a potent vasodilator. Nature, 313: 54-56.

17. Holzer $P \&$ Maggi CA (1998). Dissociation of dorsal root ganglion neurons into afferent and efferent-like neurons. Neuroscience, 86: 389-398.

18. Rang HP, Bevan SJ \& Dray A (1994). Nociceptive peripheral neurones: cellular properties. In: Wall PD \& Melzak R (Editors), Textbook of Pain. Churchill-Livingstone, Edinburgh, UK.

19. Lindsay RM, Lockett $C \& \&$ Sternberg J (1989). Neuropeptide expression in cultures of adult sensory neurons: modulation of substance $P$ and calcitonin generelated peptide levels by nerve growth factor. Neuroscience, 33: 53-65.

20. Supowit SC, Hallman DM, Zhao $\mathrm{H} \&$ DiPette DJ (1995). Bradykinin regulates neuronal calcitonin gene-related peptide expression and release. Hypertension, 26: 564 (Abstract).

21. Kawasaki H, Nuki C \& Saito A (1990). Adrenergic modulation of calcitonin generelated peptide (CGRP) containing nervemediated vasodilation in the rat mesenteric resistance vessels. Brain Research, 506: 287-292.

22. Supowit SC, Christensen MD, Westlund KN, Hallman DM \& DiPette DJ (1995). Dexamethasone and activators of the protein kinase $A$ and $C$ signal transduction pathways regulate neuronal calcitonin gene-related peptide expression and release. Brain Research, 686: 77-86.

23. Supowit SC, Hallman DM, Zhao $\mathrm{H} \&$ DiPette DJ (1998). Alpha2-adrenoreceptor activation inhibits neuronal calcitonin gene-related peptide expression. Brain Research, 782: 184-193.

24. Looi S, Ekman R, Lippton J C \& Keith I (1992). CGRP and somatostatin modulate chronic pulmonary hypertension. American J ournal of Physiology, 263: H681$\mathrm{H} 690$.

25. DiPette DJ (1999). Experimental models of hypertension. In: Izzo J L \& Black HR (Editors), Hypertension Primer: The Essentials of High Blood Pressure. Lippincott Williams \& Wilkins, Baltimore, MD, USA.

26. Supowit SC, Guraraj A, Ramana CV, Westlund KN \& DiPette DJ (1995). Enhanced neuronal expression of calcitonin gene-related peptide in mineralocorticoidsalt hypertension. Hypertension, 25: 1333-1338.

27. Supowit SC, Zhao H, Hallman DM \& DiPette DJ (1997). Calcitonin gene-related peptide is a depressor of deoxycorticosterone-salt hypertension in the rat. Hypertension, 29: 945-950.

28. Supowit SC, Zhao $\mathrm{H}$, Hallman DM \& DiPette DJ (1998). Calcitonin gene-related peptide is a depressor in subtotal nephrectomy hypertension. Hypertension, 31: 391-396.

29. Gangula PR, Supowit SC, Wimalawansa SJ , Zhao H, Hallman DM, DiPette DJ \& 
Yallampalli C (1997). Calcitonin gene-related peptide is a depressor in $\mathrm{NG}^{\mathrm{G}}$-nitro-Larginine methyl ester (L-NAME)-induced preeclampsia. Hypertension, 29: 248-253.

30. Supowit SC, Zhao H, Wang DH \& DiPette DJ (1995). Regulation of calcitonin generelated peptide expression: role of increased blood pressure. Hypertension, 26: 1177-1180.

31. Kohlmann O, Cesaretti ML, Ginoza M, Tavares A, Zanella MT, Ribeiro AB, Ramos OL, Leeman SE, Gavras I \& Gavras H (1997). Role of substance $P$ in blood pressure regulation in salt-dependent experimental hypertension. Hypertension, 29: 506-509.

32. Quirion $R$, VanRossum $D$, Dumont $Y$, St Pierre S \& Fournier A (1992). Characterization of CGRP1 and CGRP2 receptor subtypes. Annals of the New York Academy of Sciences, 657: 88-105.

33. Gardiner SM, Compton AM, Kemp PA, Bennett T, Bose C, Foulkes R \& Hughes B (1990). Antagonistic effect of human alpha-CGRP (8-37) on the in vivo regional hemodynamic actions of human alphaCGRP. Biochemical and Biophysical Research Communications, 171: 938-943.

34. Gardiner SM, Compton AM, Kemp PA, Bennett T, Bose C, Foulkes R \& Hughes B (1991). Human alpha-calcitonin gene-related peptide (CGRP)-(8-37), but not -(28-
37), inhibits carotid vasodilator effects of human alpha-CGRP in vivo. European J ournal of Pharmacology, 199: 375-378.

35. Hughes SR \& Brain SD (1991). A calcitonin gene-related peptide (CGRP) antagonist (CGRP8-37) inhibits microvascular responses induced by CGRP and capsaicin in skin. British J ournal of Pharmacology, 104: 738-742.

36. Supowit SC, Watts SW, Zhao $\mathrm{H}$, Wang D $\&$ DiPette DJ (2000). Vascular reactivity to calcitonin gene-related peptide is enhanced in subtotal nephrectomy-salt hypertension. Hypertension, 36: 701 (Abstract).

37. Yallampalli C, Dong YL \& Wimalawansa SJ (1996). Calcitonin gene-related peptide reverses the hypertension and significantly decreases the fetal mortality in preeclampsia rats induced by N(G)-nitro-L-arginine methyl ester. Human Reproduction, 11: 895-899.

38. Gangula PR, Wimalawansa SJ \& Yallampalli C (1997). Progesterone up-regulates vasodilator effects of calcitonin gene-related peptide in N(G)-nitro-L-arginine methyl ester-induced hypertension. American J ournal of Obstetrics and Gynecology, 176: 894-900.

39. Supowit SC, Zhao H \& DiPette DJ (2001). Nerve growth factor enhances calcitonin gene-related peptide expression in the spontaneously hypertensive rat. Hypertension, 37: 728-732.

40. Hoff AO, Thomas PM, Cote GJ, Qui H, Bain H \& Gagel RF (1998). Generation of a calcitonin knockout mouse model. Bone, 23: S64 (Abstract).

41. Gangula PR, Zhao H, Supowit SC, Wimalawansa SJ, DiPette DJ, Westlund KN, Gagel RF \& Yallampalli C (2000). Increased blood pressure in alpha-calcitonin generelated peptide/calcitonin gene knockout mice. Hypertension, 35: 470-475.

42. Katki KA, Supowit SC \& DiPette DJ (2000). Enhanced expression of substance $P$ in deoxycorticosterone acetate-induced hypertension. Circulation, 102 (Suppl II): II348-II-349 (Abstract)

43. Katki KA, Supowit SC \& DiPette DJ (2002). Substance $P$ in subtotal nephrectomy-salt hypertension. Hypertension, 39: 389-393.

44. Lindsay RM (1988). Nerve growth factors (NGF, BDNF) enhance axonal regeneration but are not required for survival of adult sensory neurons. J ournal of Neuroscience, 8: 2394-2405.

45. DiPette DJ \& Supowit SC (2000). Calcitonin gene-related peptide and hypertension. In: Oparil S \& Weber MA (Editors), Hypertension: A Companion to Brenner and Rector's the Kidney. W.B. Saunders Company, Philadelphia, PA, USA. 